\title{
Exocrine Pancreatic Cancer pN1a TNM Finding
}

National Cancer Institute

\section{Source}

National Cancer Institute. Exocrine Pancreatic Cancer pN1a TNM Finding. NCI

Thesaurus. Code C60951.

Exocrine pancreatic cancer with metastasis to a single regional lymph node. (from CAP Cancer of the Endocrine Pancreas Protocol- January 2005 Revision) 